\title{
Covid-19 Effects on the Medications Used to Treat Diabetes
}

\section{Robert G Smith}

Shoe String Podiatry Ormond Beach, Florida, North America, USA

*Correspondence Author: Robert G Smith, Shoe String Podiatry Ormond Beach, Florida, North America, USA.

Received date: August 07, 2020; Accepted date; August 19, 2020; Published date: August 25, 2020

Citation: Robert G Smith., (2020) Covid-19 Effects on the Medications Used to Treat Diabetes. J Pharmaceutics and Pharmacology Research. 3(1); DOI: $10.31579 / 2693-7247 / 008$

Copyright: () 2020 Robert G Smith, This is an open-access article distributed under the terms of the Creative Commons Attribution License, which permits unrestricted use, distribution, and reproduction in any medium, provided the original author and source are credited.

\section{Abstract}

Minority patients taking prescription drugs for diabetes mellitus and hypertension are sick and vulnerable. They should not be subjected to poor quality medications that can make them worse. The purpose of this review is to present data fortifying an argument that Covid-19 will continue to disproportionally effect minorities who suffer with Type 2 Diabetes Mellitus, Hypertension, and GI ulcer disease by limiting drug safety for pharmaceuticals that are imported from oversea manufacturers even after the pandemic is over. As a foundation an overview of the Food and Drug Administration (FDA) overseas inspection process that have been validated by previously published reports will be offered to accent the procedural process. Limitations and challenges to the overseas drug inspection process as documented by congressional leadership and the FDA are offered. An accurate scientific description of Nnitrosodimethylamine (NDMA) will be presented to emphasize its danger to these patients. Five key points or initiatives recently published by the FDA to assist in food and drug safety from overseas manufacturers during the Covid-19 pandemic will be presented.

Keywords: covid-19; treat diabetes; medications

\section{Introduction}

The effects of COVID-19 on the health of racial and ethnic minority groups is still being studied. Data suggests a disproportionate burden of illness and death among racial and ethnic minority groups. A recent MMWR report included race and ethnicity data from hospitalized with lab-confirmed COVID-19 found that $45 \%$ of individuals for whom race or ethnicity data was available were white, compared to $59 \%$ of individuals in the surrounding community. ${ }^{1}$ However, $33 \%$ of hospitalized patients were black, compared to $18 \%$ in the community, and $8 \%$ were Hispanic, compared to $14 \%$ in the community. These data suggest an over-representation of blacks among hospitalized patients. ${ }^{1}$ Among the 178 adult study population had data consistent with having one or more underlying conditions described as the following: the most common were hypertension $(49.7 \%)$, obesity $(48.3 \%)$, chronic lung disease $(34.6 \%)$, diabetes mellitus (28.3\%), and cardiovascular disease (27.8\%). [1] In the United States, 34.2 million or $10.5 \%$ of the total population have diabetes mellitus. [2] Among those aged 65 years or older, a population at higher risk for death from COVID-19, 26.8\% have diabetes mellitus.[2] Muniyappa and Gubbi summarize that individuals with diabetes mellitus, hypertension, and severe obesity (BMI $40 \mathrm{~kg} / \mathrm{m}^{2}$ ) are more likely to be infected and are at a higher risk for complications and death from COVID-19. [3] Gautam et al reported that diabetes mellitus has well known costly complications but wanted to show through a retrospective model that costs of care for chronic pain treated with opioid analgesic medications would also be substantial. [4] They found that higher costs of care for opioid-treated patients appeared for all types of services and likely reflects multiple factors including morbidity from the underlying cause of pain, care and complications related to opioid use, and poorer control of diabetes as found in other investigations. [4] Ethnic minority populations in the United States are disproportionately affected by cardiovascular disease (CVD) risk factors, including hypertension, overweight/obesity, and diabetes.[4,5] An attractive inference can be made that a clinician would utilize metformin, angiotensin II receptor blockers (ARBs), and $\mathrm{H}_{2}$ antagonists to treat these chronic conditions in a patient diagnosed with Type 2 diabetes mellitus. Given, this inference and the reality that $N$-nitrosodimethylamine (NDMA) has been detected in toxic levels by the Food and Drug Administration (FDA) in these pharmaceuticals allows for a concern to be voiced that these patients may be exposed to this carcinogen. The purpose of this review is to present data fortifying an argument that Covid-19 will continue to disproportionally effect minorities who suffer with Type 2 Diabetes Mellitus, Hypertension, and GI ulcer disease by limiting drug safety for pharmaceuticals that are imported from oversea manufacturers even after the pandemic is over. First, as a foundation an overview of the Food and Drug Administration (FDA) overseas inspection process that have been validated by previously publish will be offered to accent the procedural process. Secondly, limitations and challenges as documented by congressional leadership and the FDA agency itself as they are describing their overseas inspection process will be offered. Thirdly, an accurate scientific description of $N$-nitrosodimethylamine (NDMA) will be offered to emphasize its danger to these patients. Lastly, five key points or initiatives recently published by the FDA to assist in food and drug safety from overseas manufacturers during the Covid-19 pandemic will be offered.

\section{FDA Overseas Inspections}

A pharmaceutical manufacturer may be held liable for product defect if the product is unreasonably dangerous. Four basic elements define how a pharmaceutical product can be legally considered to be defective: (1) manufacturing defects, (2) warning defects, (3) design defects, and (4) marketing defects. Because pharmaceutical products are produced according to exacting standards, 
with close FDA (Food and Drug Administration) oversight and frequent facility inspections, it is rare for there to be a viable manufacturing defect case involving pharmaceutical products. FDA is responsible for overseeing the safety and effectiveness of all drugs marketed in the United States, regardless of where they are produced and conducts inspections of both foreign and domestic drug manufacturing establishments. Drug manufacturing defects to include the impurity "N-Nitrosodimethylamine" (NDMA) have been reported in a number of medications that are consumed by Type 2 diabetic patients: metformin, angiotensin II receptor blockers (ARBs), and $\mathrm{H}_{2}$ antagonists manufactured in foreign drug manufacturing plants.

As previously published Senate Finance Committee Chairman Chuck Grassley of Iowa sent a letter on August 7, 2019 to Department of Health and Human Services (HHS) Secretary and Food and Drug Administration (FDA) Acting Commissioner urging them to reinstate unannounced inspections of prescription drug manufacturing facilities in foreign countries in light of the administration's new "Safe Importation Action Plan" as well as the fact that these facilities provide most of the ingredients for production inside the United States. Therefore, it is important to determine more accurately if these facilities meet set standards of quality and safety for both domestic and importation purposes. [6,7] Further, Grassley's published letter highlighted that the FDA in 2014 unveiled a pilot program in India, the senator noted, that cut out advance notice of an inspection in lieu of either short notice or an unannounced visit. [6] Grassley describes that this program also provided that FDA inspectors arrange their travel through U.S. embassies versus FDA offices or manufacturer-arranged travel so there was more secrecy ahead of an inspection.[6] Under that program, the FDA saw a $60 \%$ increase in the number of warnings it issued to manufacturers, he said. In 2015 this pilot program ended. [6,7] In defense to Senator Grassley's letter Stephen M. Hahn, Commissioner of Food and Drugs wrote and published to Senator Grassley's letter with a response letter dated February 12, 2020 that describes the: Notice of Proposed Rulemaking (NPRM) with its two pathways published on December 23, 2019.[8]

Of interest is that the United States increase dependency on foreign manufacturers for prescription and generic drugs, the Food and Drug Administration is plagued with the problem of conducting overseas inspections of drug manufacturing plants is gaining attention. As recently as May 2020, it has been reported that only 26 percent of facilities manufacturing active pharmaceutical ingredients and a minority of 46 percent of the facilities producing finished dosage forms for human drug consumption for the U.S. market were actually in U.S.[9] Drugs manufactured overseas must meet the same statutory and regulatory requirements as those manufactured in the United States. FDA's Center for Drug Evaluation and Research (CDER) establishes standards for the safety, quality, and effectiveness of, and manufacturing processes for, over the counter and prescription drugs. CDER requests that FDA's Office of Regulatory Affairs (ORA) inspect both domestic and foreign establishments to ensure that drugs are produced in conformance with applicable laws of the United States, including current good manufacturing practice (CGMP) regulations. [9] FDA investigators generally conduct three main types of drug manufacturing establishment inspections: preapproval inspections, surveillance inspections, and for-cause inspections. [9] The Trump administration announced the formerly-bankrupt, half-dead company, Eastman Kodak, will collect a $\$ 765$ million federal loan to transform itself into a pharmaceutical manufacturing company, making ingredients for use in generic drugs to alleviate America's dependency on foreign counties for pharmaceuticals.
From 2012 to 2016, the FDA did increase the number of foreign inspections it conducted. [9] The number of inspections of foreign drug manufacturers has declined since fiscal year 2016, which the FDA attributes in part to fewer inspectors and difficulty filling jobs abroad. Most foreign inspections are preannounced, giving manufacturers time to prepare for inspections.[9] The FDA does conduct surprise foreign inspections, but not many, and the exact number is not known, per Mary Denigan-Macauley, the Governmental Accounting Office Health Care Director.[9] Further, despite calls for more inspections, both foreign and domestic inspections decreased by 10 percent and 13 percent respectively from fiscal 2016 through fiscal 2018.[9]

\section{FDA Overseas Inspection Challenges}

The FDA offers documentation that in $2010,64 \%$ of foreign manufacturing plants, predominantly in India and China, had never been inspected by the FDA.[9,10] Alarmingly by the year 2015, 33\% of these plants still remained uninspected. $[9,10]$ The U.S. Food and Drug Administration has struggled for more than a decade with language barriers when inspecting foreign drug manufacturing facilities and frequently relies on translators provided by the companies under examination, raising questions about impartiality and accuracy of information, a government investigator told lawmakers.[10-14] The FDA inspections are riddled with problems because the FDA admittedly doesn't have enough translators, inspectors are often forced to rely on the drug manufacturer to provide reports that can raise questions about the accuracy of information FDA investigators collect. [10-14] The FDA admits that generally it does not send translators on inspections in foreign countries. FDA investigators rely on the pharmaceutical industries to provide translation services, which can be an English-speaking employee of the industry being inspected, an external translator hired by the industry, or an English-speaking consultant hired by the industry [1014]. This may not be big problem in India but it may be challenging in parts of Asia, including China and Japan [10-14]. Unlike domestic inspections, which are all unannounced, the vast majority of overseas firms have months of advance warning of an FDA visit, giving them plenty of time to prepare. [10-14]

In Eban's previously published works describes tactics and examples that foreign pharmaceutical manufacturers have done to avoid being inspected by the FDA. [15] First. Inspectors discovered that vials made by Wockhardt had tested contained black metallic particles which came from defective sterilizing equipment and were potentially deadly and had failed visual inspection. [15] The investigators followed documents that uncovered a formulation area that had not disclosed to the FDA, where the company was using corroded sterilizing equipment to make both insulin and injectable adenosine.[15]

Another example Eban describes took place in a facility in West Bengal, India, that manufactured chemotherapy drugs for the German pharmaceutical company Fresenius Kabi Oncology.[15] The investigators discovered not all the plant's files, were stored on its main server making it difficult to conduct a complete inspection. [15] Moreover, Eban asserts and describes another example of FDA investigators visiting a facility in Punjab, India, where Ranbaxy Laboratories made atorvastatin calcium. ${ }^{15}$ According to the inspection report, in the quality-control laboratory, they found dozens of workers hunched over documents and back dating them. ${ }^{15}$ Also, while inspectors examined the plant's computer systems, they discovered even more consequential falsifications. [15] 
Another incident describes FDA investigators showed up unannounced at an Akorn India facility in Himachal Pradesh.[15] The testing data appeared to be in perfect order; data worksheets in the microbiology laboratory showed that samples had been prepared, incubated, and examined but these samples were not presented to the investigators. ${ }^{15}$ An additional incident describes FDA investigators visit to a facility in Punjab, India, run by Parabolic Drugs. [15] During the inspection, an investigator claimed to have found a filthy, small, locked laboratory, its entrance partially blocked by a piece of bulky equipment. ${ }^{15}$ Also, some of those test results were not entered into the plant's official data system, which, the inspectors wrote, was "necessary to assure compliance. [15]

Another of Eban's example where FDA investigators visited a Mylan Laboratories facility in Nashik, Maharashtra, after a whistleblower claimed that employees were deliberately corrupting data.[15] Upon inspection it was discovered that the plant's software system was riddled with error messages.[15] Plant managers had apparently conducted no investigation into the repeated crashes.[15] The FDA suspected that the crashes had been intentional, just as the whistleblower had alleged.[15]

Eban illuminates another published account where FDA investigators visited a facility in northeastern China run by Zhejiang Hisun, the country's largest exporter of pharmaceutical ingredients to the United States.[15] At the plant's quality-control laboratory, an investigator searched the grid of computer audit trails and figured out that the plant was secretly pretesting its drug samples and masking the results. [15] In one instance, the FDA claims, technicians had disabled the audit trail, run 80 covert tests, then turned the trail back on two days later.[15]

The last example is as well as the most outrageous described by Eban published account occurred while on an inspection to a facility in northeastern China where Zhejiang Bangli Medical Products manufactured lidocaine and capsaicin skin patches for treating pain. ${ }^{15}$ Soon after the investigator and her translator began their work, worried company officials started interrogating them and questioning their authority to inspect.[15] After the firm's general manager became visibly upset, the inspectors went to gather their things in the conference room. The general manager refused to let them leave, effectively imprisoning them, and called the police, who, according to the FDA, claimed their credentials were fake.[15] More than an hour later, after the intercession of Chinese drug regulators, the FDA employees were finally freed.

Lastly according to Eban's published reporting, the FDA downgraded recommended sanctions against Indian plants 109 times between 2013 and 2018.[15] Further, Eban has asserted: "The FDA is knowingly allowing unsafe, substandard drugs from noncompliant plants into the U.S., over the recommendations of its own investigators." [15]

\section{N-nitrosodimethylamine (NDMA)}

Over the last decade relation to N-Nitrosodimethylamine (NDMA) found in water and wastewater has been reported. Chloramination is the most common process that results in formation of NDMA during water and wastewater treatment. However, ozonation of wastewater or highly contaminated surface water can also generate significant levels of NDMA. ${ }^{16}$ White has reported and published that $N$-nitrosodimethylamine (NDMA) is a hepatotoxic agent and carcinogen contaminant in commonly used medications such as valsartan, losartan, irbesartan, and ranitidine.[17] It can be argued that a patient suffering from Type 2 diabetes is more at risk for hepatotoxicity from the impurity NDMA because of the pathogenesis of Type 2 diabetes mellitus. The Food and Drug Administration has established a maximum dose of NDMA that is permissible per tablet and guidance for manufacturers. White has taken the position through his publications that many unanswered questions about NDMA contamination facilitates the need for rigorous FDA investigation. [17] According to FDA communications the acceptable human daily intake of NDMA is 96 nanograms or 0.32 parts per million. NDMA can be found in medications from the drug's manufacturing process, the medication's chemical structure, or storage or packaging conditions. [18]

NDMA was one of several nitrosamine impurities implicated massive product recalls because the population at risk of exposure has vastly increased allowing for minority populations to be greatly effective from inaction. In April 2020, the FDA required the removal of all ranitidine products from the market after it was discovered that NDMA levels could increase over time under normal storage conditions and that higher levels were associated with products that had a longer length of time since they were manufactured. [18, 19] In addition, NDMA was found to increase significantly in ranitidine samples stored at higher temperatures. Specifically, unacceptable levels of this potentially carcinogenic impurity have been identified in products manufactured by 5 different firms that the FDA is working with these manufacturers to begin recalls. $[18,19]$ Lastly, fortunately not present in samples of the plain metformin active, elevated levels of NDMA Have been found in finished-dose tablets of the Metformin ER formulation. [18, 19]

\section{Key points regarding Foreign Drug Inspections}

The COVID-19 pandemic has brought some challenges to the FDA yet the agency has stated they continue to utilize and implement additional alternative inspection tools and approaches while postponing foreign and domestic routine surveillance facility inspections.[9] This will continue as conditions warrant, except for certain mission critical inspections, including pre-approval and forcause assignments.[9] As a result of the COVID-19 pandemic, most foreign and domestic surveillance facility inspections are currently postponed.[9] Only inspections deemed mission critical will be considered on a case-by-case basis as this outbreak continues to unfold. The FDA announced it will employ additional tools to ensure the safety of products imported to the U.S., which have proved effective in the past.[9] These will include: denying entry of unsafe products into the U.S.; physical examinations and/or product sampling at the U.S. borders; reviewing a firm's previous compliance history; using information sharing from foreign governments as part of mutual recognition and confidentiality agreements; and requesting records "in advance of or in lieu of" on-site drug inspections.[9] Five key points that were accentuated during the June 2, 2020, the U.S. Senate Committee on Finance held hearing centered on FDA's oversight of the global pharmaceutical supply chain included: the FDA stands behind the agency's foreign inspection practices, the FDA is under pressure to increase unannounced foreign inspections, the FDA believes "alternative tools" are adequate to ensure the quality of foreign manufactured drugs during the COVID-19 pandemic, the FDA offered no indication as to when it will resume international drug inspections, and there is a clear push for more domestic drug manufacturing and solutions to drug shortages.[9]

\section{Conclusions}


Fifty years ago, the pharmaceutical industry moved away from the United States traveled first to Puerto Rico in response to tax incentives, and then to Europe and nations that were developing at the time, such as China and India. Therefore, the clear push for more domestic drug manufacturing to be the solution to drug shortages lacks any financial incentives for pharmaceutical companies to return to the United States. The return of drug manufacturing to the United States is a clear challenge for the FDA. Secondly, the FDA is under pressure to increase unannounced foreign inspections, given the current pandemic this is a significant challenge for the FDA and is unlikely. The FDA believes that "alternative tools" will be adequate to ensure the quality of foreign manufactured drugs during the COVID-19 pandemic, this belief is centered on creative magical thinking. Given, that announced FDA foreign inspections were confronted with obstacles to the point of holding an inspector hostage. It is unlikely that alternative tools to ensure the safety of the United States drug supply chain can take the place of unannounced FDA foreign inspections. The current COVID-19 pandemic will curtail unannounced foreign inspections especially given that the lack of FDA employees willing to perform foreign drug supplier inspections exist. The lack of key employees to perform inspections will result in more medication contamination that will affect the diabetic patient because an honor system will ultimately fail.

Minority patients taking prescription drugs for diabetes mellitus and hypertension are sick and vulnerable; they should not be subjected to poor quality medications that can make them worse. It is expensive, logistically challenging, and politically unpalatable for the FDA to show up for unannounced inspections of foreign drug manufacturing plants. If the FDA is not given funding to increase testing of foreign medications, it should not be subject United States citizens to the potential impurities and contaminates in the United States drug supply chain. Only with proactive FDA approach to ensure the United States drug supply will become the safest in the world.

\section{References:}

1. Garg S, Kim L, Whitaker M, et al.(2020) Hospitalization Rates and Characteristics of Patients Hospitalized with Laboratory-Confirmed Coronavirus Disease 2019 COVID-NET, 14 States, March 1-30, 2020. MMWR Morb Mortal Wkly Rep 69:458-464.

2. Centers for Disease Control and Prevention. National Diabetes Statistics Report, 2020. Atlanta, GA: Centers for Disease Control and Prevention, US Department of Health and Human Services, 2020.
3. Muniyappa R, Gubbi S. (2020) COVID-19 pandemic, coronaviruses, and diabetes mellitus. Am J Physiol Endocrinol Metab. 318(5): E736-E741.

4. Gautam S, Franzini L, Mikhail OI, Chan W, Turner BJ.(2016) Novel Measure of Opioid Dose and Costs of Care for Diabetes Mellitus: Opioid Dose and Health Care Costs. $J$ Pain. 17(3):319-327.

5. Commodore-Mensah Y, Selvin E, Aboagye J, et al.(2018) Hypertension, overweight/obesity, and diabetes among immigrants in the United States: an analysis of the 20102016 National Health Interview Survey. BMC Public Health; 18(1):773.

6. Grassley Urges HHS, (2019) FDA to Implement Unannounced Inspections of Foreign Drug Manufacturing Facilities. Newsroom Chairman's News.

7. Keenam J.(2019) With importation on tap, Grassley urges FDA to inspect drug plants "unannounced".

8. Stephen M. Hahn, (2020) Commissioner of Food and Drugs.

9. McMeekin, J. PHARM. D., (2020) Associate Commissioner for Regulatory Affairs. Food and Drug Administration Statement before the committee on finance, United States Senate. Covid-19 and Beyond: Oversight of the FDA's Foreign Drug Manufacturing Inspection Process.

10. Miessler J. (2020) Lawmakers Outraged over Ineffectiveness of FDA's Foreign Inspections Program.

11. Lawmakers Press (2020) CDER's Woodcock on Foreign Inspections.

12. White MC. Why your generic drugs may not be safe? Chicago Sun Times.

13. White MC. (2019) Why Your Generic Drugs May Not Be Safe and the FDA May Be Too Lax.

14. Challenges for FDA with Foreign inspections. Pharmatutor Pharmacy Infopedia. (2020)

15. Eban K. (2019) 8 Ways Overseas Drug Manufacturers Dupe the FDA Wired.

16. Sgroi M, Vagliasindi FGA, Snyder SA, Roccaro P. (2018) NNitrosodimethylamine (NDMA) and its precursors in water and wastewater: A review on formation and removal. Chemosphere. 191:685-703.

17. White CM. (2020) Understanding and Preventing ( $N$ Nitrosodimethylamine) NDMA Contamination of Medications. Ann Pharmacother. 54(6):611-614.

18. PubChem, U.S. National Library of Medicine. (2004) Compound summary: N-nitrosodimethylamine.

19. U.S. Food and Drug Administration.(2019) Questions and Answers: NDMA impurities in ranitidine (commonly known as Zantac.) 
This work is licensed under Creative Commons Attribution 4.0 License

To Submit Your Article Click Here: Submit Manuscript

DOI:10.31579/jppr.2020/008
Ready to submit your research? Choose Auctores and benefit from:

* fast, convenient online submission

* rigorous peer review by experienced research in your field

* rapid publication on acceptance

* authors retain copyrights

* unique DOI for all articles

* immediate, unrestricted online access

At Auctores, research is always in progress.

Learn more www.auctoresonline.org/journals/pharmaceutics-andpharmacology-research 